\title{
The Transformation of the Great Decommissioned Farini Railroad Yard: The Research for a Modern Housing Settlement
}

\author{
Raffaella Neri and Tomaso Monestiroli
}

\begin{abstract}
The paper deals with the theme of the transformation of the large abandoned areas of the city, of their new destination, of the role of parks and gardens in the construction of the modern city, of the research on the housing units settlement principles. The essay collects several projects carried out over time: they are the results of a national PRIN research.
\end{abstract}

Keywords Railroad yard · Housing - Urban composition · Housing units

\section{The First Project, 2009}

The Farini railroad yard is an important and strategic site due to its remarkable extension and availability as well as to its now central location within the city, its connection with the transportation network and the proximity of its urban facilities. As such, it is a part of the city that needs to be reconceived and rebuilt. How? Based on which city concept? By building what connections and based on which principles and elements?

From the urban planner's point of view, a preliminary question should be asked when approaching this issue: given the area's high potential, would it be possible to build a new and challenging high-density settlement, a modern development within the nineteenth-century city, without creating yet another suburb-albeit a luxury one, gravitating on the city of Milan - and use it as an opportunity to redesign the built tissue surrounding it? What conditions would lead to such an outcome? And, given that concentration and building density allow for a more limited use of surface, both in the undeveloped areas around the city and at its very core, what does it mean to

\footnotetext{
${ }^{1}$ Design Group, Antonio Monestiroli, coordinator, with Ilario Boniello, Massimo Ferrari, Stefano Guidarini, Tomaso Monestiroli, Raffaella Neri, Claudia Tinazzi Coll. Marcello Bondavalli, Lorenzo Margiotta, Guido Rivai.
}

R. Neri $(\varangle) \cdot$ T. Monestiroli

Architecture, Built Environment and Construction Engineering-ABC Department, Politecnico di Milano, Milan, Italy

e-mail: raffaella.neri@polimi.it

(C) The Author(s) 2020

S. Della Torre et al. (eds.), Regeneration of the Built Environment

from a Circular Economy Perspective, Research for Development,

https://doi.org/10.1007/978-3-030-33256-3_19 
promote the development of this area rather than of others, in a context that can only be considered at the territorial scale?

The city administration's decision to consolidate the central core of Milan by developing great building volumes necessarily implies that the new district is adequately connected with the road and public transportation — both road and railwaybased - networks, and that these are reviewed and adequately upgraded. In other words, for the new development to become a part of the city, it must be accessible and well connected to the urban and territorial system.

A second important issue that should be considered to prevent the area from becoming a suburb within the city revolves around the activities it will accommodate, which should be different, mixed and above all include urban interest facilities that might contribute to it becoming a new centre open to the city, and would make the site recognizable and the district an identifiable part of the city. The multiplicity of activities reflects the richness and diversity of collective and private spaces. The mission of architecture is to interpret such richness and to create places that convey character and quality.

Starting from such considerations, we have approached the issue of design in order to define several elements including the composition principles that would support the construction of a both coherent and articulated new city sector; the basic housing units and their building types, as different from the old city blocks; the collective places and their character, the connections between buildings and open spaces, the role of green spaces, the relation between facilities and housing, between commercial facilities and other programs.

The tracks and the railroad yard cut through and separated entire sectors of the city which have grown independently and created an interruption in the rings of the Beruto Plan. The building blocks developed from Corso Sempione had to stop against the railway; the so-called Isola district, developed at the east around the old road to Como, had also to be interrupted; other outer districts were developed around the old cores of Dergano, Affori, and Bovisa in the northern direction along the railway and the lines that connect Milan to other destinations. Since the early twentieth century, the city has grown beyond the railway and its continuing role of separating void.

The order and location of the settlement are decided by the railway, the main line connecting Milan to its surroundings. An expressway also runs alongside the tracks and given its interurban character, only has one point of access in the district, a non-pass-through rest area close to the business centre.

The system of road infrastructure is defined by a hierarchical principle, the goal of which is to give coherence to the settlement. The urban and interurban road network runs along the outer borders with two expressways - one alongside the tracks and the other straddling the tracks to unite via Caracciolo and via Lancetti. A new urban road connects the blocks to the south, along the border of the park; the existing perimeter roads define the area and connect it to the neighbouring districts; finally, the inner roads, of different capacity and role, define a regular grid made of 140 metres green squares within which the buildings are located. 
The hierarchical order reflected by the roads sorts traffic by destination, directs cross traffic to the expressways, and as a consequence only allows for traffic serving the housing and other local activities into the area itself.

The focal point at the north-west apex of this almost triangular area where the interrupted thoroughfares that articulate the city and its territory still converge is the point from which the settlement can be organized and provided with an internal hierarchy to define and articulate the elements of the new district.

The unique character of the north-west apex of the system is expressed in the plan by the exceptional urban quality of the activities and by the architecture that represents them - a system of office and hotel towers organized around a square that becomes the core of the settlement, completed by a building for cultural activities open to the entire city (museum, auditorium, etc.). The 37- and 29-storey iron and glass towers become the beacon of the new district and of the surrounding territory (Fig. 1).

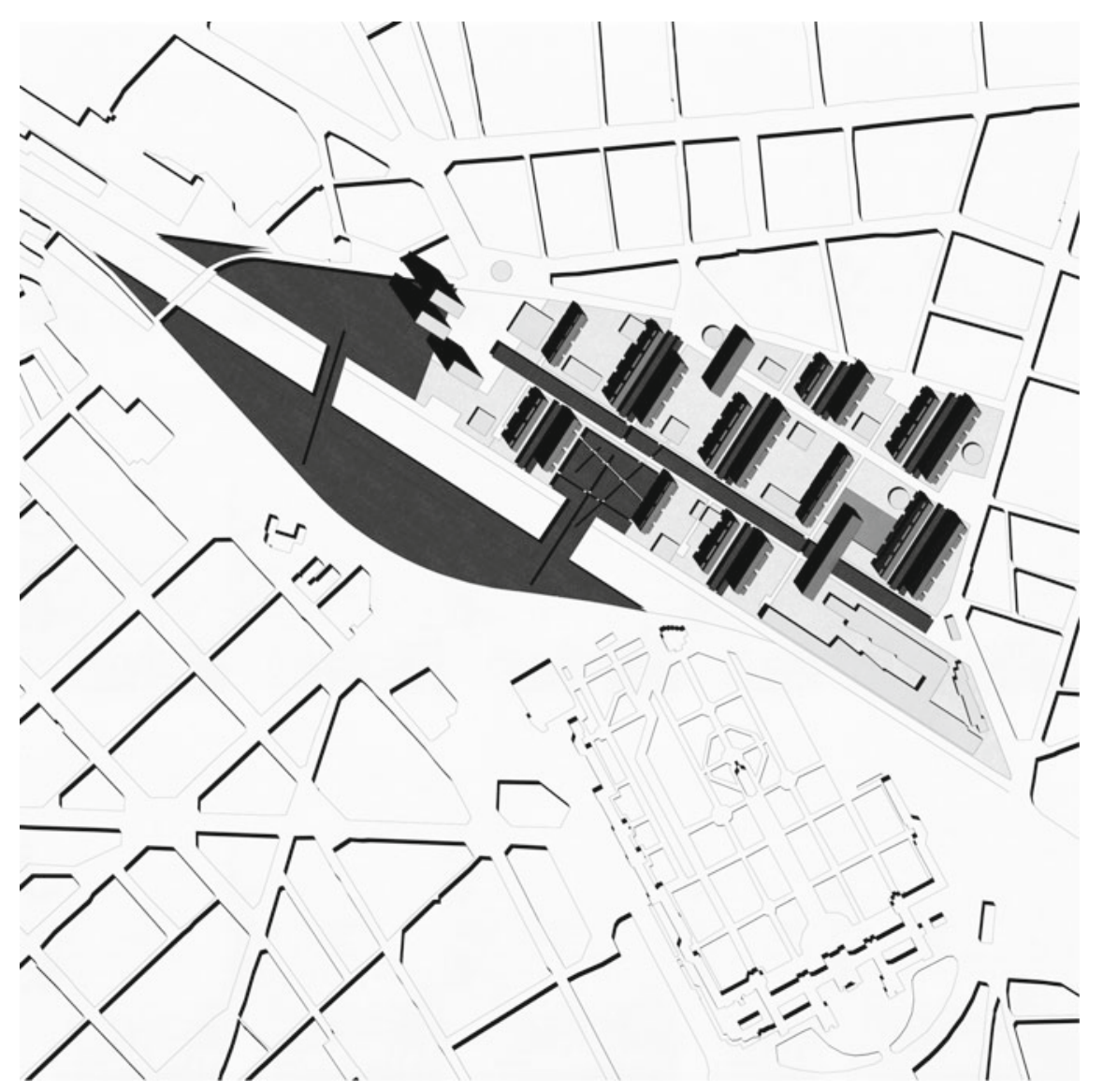

Fig. 1 Plan of the project 
The development is surrounded by green spaces—partly landscaped and planted, partly lawns surrounded by rows of trees-open to public use. The presence of green spaces and the definition of the relation between buildings and open and landscaped spaces is an unavoidable issue in the construction of the modern city. From the relation between city and rural areas to the definition of the character of urban green spaces (parks, gardens, courtyards, or squares), it implies the precise definition of how green areas contribute to the design of a new development, how buildings define open spaces. In more general terms, the main issue is the role of green spaces in the use and composition of places.

The plan concentrates the buildings in a portion of the area in order to create an extended forest-like park which connects the districts separated by the railway. The pedestrian routes and bike lanes in the park establish the relation between the two city sections. Long rows of trees border the thoroughfares that articulate the district, highlight their importance and define the lawns that accommodate the new buildings, and replace the old urban blocks. As defining elements of the new development, the green spaces have different qualities, layouts, and characters based on their relations with the buildings, size, and treatment. The green spaces include the urban ground from which the buildings rise, divided into "rooms" for private housing and collective facilities, as well as the park, gardens, lawns, and rows of trees typical of Lombardy's landscape.

Another hub of collective activities is located in the decommissioned customs across from the main square and accommodates the primary schools and sports facilities, public gyms, and swimming-pools.

The two hubs are connected by a central green thoroughfare that runs alongside the railway tracks and articulates the entire district as a sort of Rambla along which the main commercial and collective facilities are located: a pond, an 18-storey bridge building for studios and workshops, a garden that straddles the tracks and connects the development to the park and the section south of the railway. Other collective and commercial facilities for the district are located on another axis alongside the Rambla.

The definition of housing as made of minimum repeatable units based on the development of a rule and its possible variations are a thread that runs through the history of the city - the development of the block bordered by roads, in everchanging shapes based on the same principle, guided the construction of cities up until the twentieth century.

Can the block be replaced in the fabric of the modern city? Is it still necessary to define a settlement principle for housing, the most relevant urban element in terms of quantity in the development of the city, as a principle that can match, or at least point to, the diversity of places that was typical of the ancient city?

The housing proposed in the plan looks out onto green spaces, the open courtyards' lawns, the tree-lined roads, and the park. The old enclosed blocks open up and acquire a new character and a green heart-a collective area with different facilities measured by the relation between the houses. 
The presence of such facilities introduces a principle of variation that makes the different places recognizable and the courtyards themselves busy and full of life, each with its own characters. Their openness means that the green spaces can be crossed and perceived as even more extended than they are, as well as well connected to the spaces at the centre of the district.

The hierarchical structure of the settlement defines the character of the courtyards based on their specific location-close to the Rambla, or to the roads that run alongside the area and the small squares that accommodate the neighbouring roads, occupied by the pond, fronting the garden, etc.

This settlement principle is reflected in the structure of the housing, the main quality of which is the diversity of frontages. The frontages may have either a full brick enclosure, corresponding to the sleeping areas that look out onto the inner tree-lined roads or a mixed glazed enclosure for the living areas, large light-filled verandas that look out onto the lawn of the courtyards. The 12-storey houses are perpendicular to the district's roads and laid out alternately so as to define basic units built on the system of small and large courtyards.

Special housing units such as the residences for students and senior citizens have a different character due to their particular location, with a double volume and double frontage in correspondence with the lawns and glazed living rooms on both sides.

The buildings that accommodate working activities, such as professional studios and workshops, also introduce variations in terms of location and type, as they are slightly taller and built as bridges straddling the two main roads that define the system. They are organized as large lofts that can be combined for specific requirements and become secondary reference points that measure the distances within the district's regular grid.

Facilities and collective buildings are distributed within the courtyards, along the two main roads. The facilities include mainly commercial activities that can be located below the ground level, or cinemas, theatres, and auditoriums that require no direct lighting and are perceived as large glazed atria on the lawn, large skylights that direct the light, and people in the underground spaces so that the surface can be occupied as much as possible by green spaces.

The distribution of activities in the area is based on the criteria of importance and easy accessibility - the urban museum and auditoriums are in the main square, commercial and catering activities are along the Rambla and the parallel road, recreational activities are close to the pond, kindergartens and primary schools are in more protected courtyards, administrative and health-care facilities define the smaller squares on the area's perimeter, close to the outer districts, cinemas and cultural activities are close to the urban railway stop, the library is in a quiet green area, etc. 


\section{The Second Project, $2012^{2}$}

The research has been further detailed in a second master plan conceived by Antonio Monestiroli that confirms the first master plan's general layout but proposes blocks and housing units that, while always open and green, develop a possible interior complexity that creates places of different nature, character, and measurement, defined by the relation between different kinds of houses, facilities, and green spaces.

Based on this proposal, we have decided to test the general elements of its principle, to assess its potential, and allowance for variation, as it usually happens with the construction of the city.

We selected the general features, and we considered unassailable and translated them into a master plan, a framework within which many groups could develop their designs: the only constraints we indicated, in order not to compromise the main principles, were the general layout, the grid of open blocks with a central green space, the construction of its borders along the distribution roads, and the coexistence of different housing types (Fig. 2).

Since we consider green space a truly fundamental element in the construction of the modern city and its many collective areas, the core of the block is a park in the master plan we have developed-green squares along with gardens, parks, fields, and places that currently lack a precise identity may be described and defined by the buildings and their connections.

Urban parks have long been traditional places of the city. Milan has the Sempione Park, or the Porta Venezia Gardens, among others, just like Rome, Paris, and Berlin have their own famous parks. As metaphors of the rural areas outside the city walls,

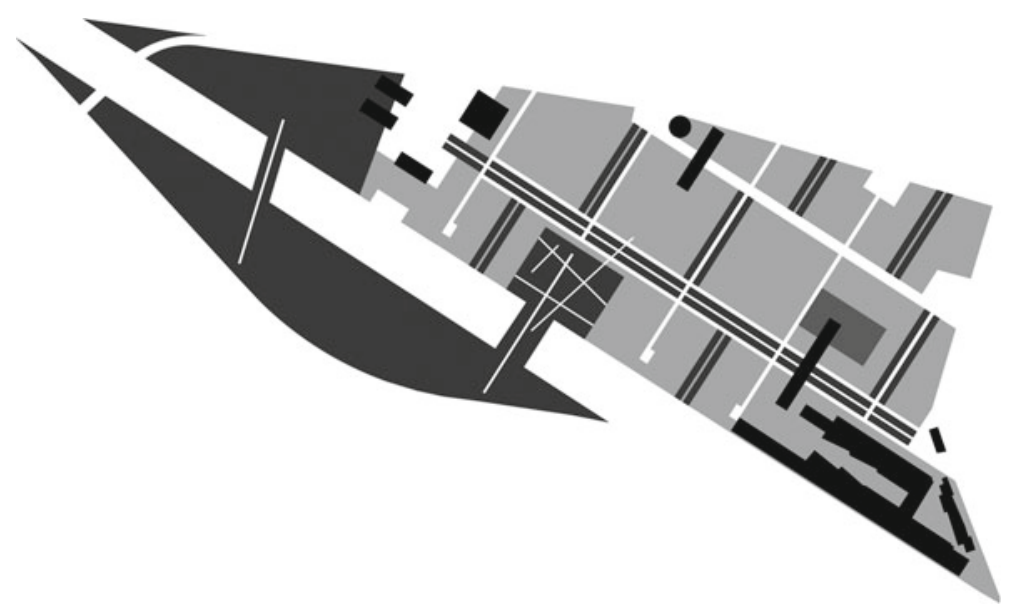

Fig. 2. Structure of the settlement and the public green spaces

\footnotetext{
${ }^{2}$ See Footnote 1. Design Group, Antonio Monestiroli, coordinator, with Claudia Tinazzi, Fabio Sebastianutti, Luca Cardani.
} 
and destinations for leisure, promenades, hangout, and parks are fully and truly public places that have rightfully become part of the city. In American cities like New York or Chicago, the presence of green areas means higher real estate values: in cities that have no real tradition of squares, large parks are true urban collective spaces, the core of public life. They characterize their districts just like churches used to characterize theirs in the past and qualify the housing that enjoys their view, proximity, and presence.

But can green spaces at a smaller scale, with a different identity and size, characterize the places of housing and even be the place of the house?

The second condition we wanted to experiment was the coexistence of different kinds of housing and ways of living and connecting the house with its surroundings in the same block, thus creating different housing environments.

The block may be a mixed unit that includes several building types each developing its own spaces that coexist and interrelate: the courtyard, the aligned house, the tall house, and their complements - the space of the courtyard, the frontage of the aligned house, and the view from the tower. Facilities, workshops, offices, and shops also contribute to the definition of these collective places within the block.

We expect this unit to express both a general principle that is as recognizable as that of the old city and formal features that may change based on the location, requirements, activities it accommodates, and on the buildings it includes, so that each block is different, unique, and identifiable; the city represents a community that is the sum of many different individuals. The only way to transform the "tumult in the whole" into a rich environment is a clear order in the housing models.

\section{The Second Project, 2012. First Variation ${ }^{3}$}

The project explores a possible variation within the previously established principles of organization of the block and based on the observation of the modern city and the studies on the changing house-street relationship.

In the project, here proposed each block incorporates public urban space-a green space that expands in the combination of the blocks themselves, and is at the same time a place the houses look out onto, a public collective facility, a place of distribution to the buildings and the activities there located, and a place of life for the residents and of facilities open to the city. Being only accessible by pedestrians and bicycles, it is separated from the streets that divide the different blocks and are merely for service and car access to the buildings.

Several separated places, alternated in succession, look out onto the central green area: houses and buildings for collective activities are articulated to provide open courtyards and small squares, also green, and are intentionally conceived to establish

\footnotetext{
${ }^{3}$ See Footnote 1. Design Group, Raffaella Neri, coordinator, with Federica Cattaneo.
} 


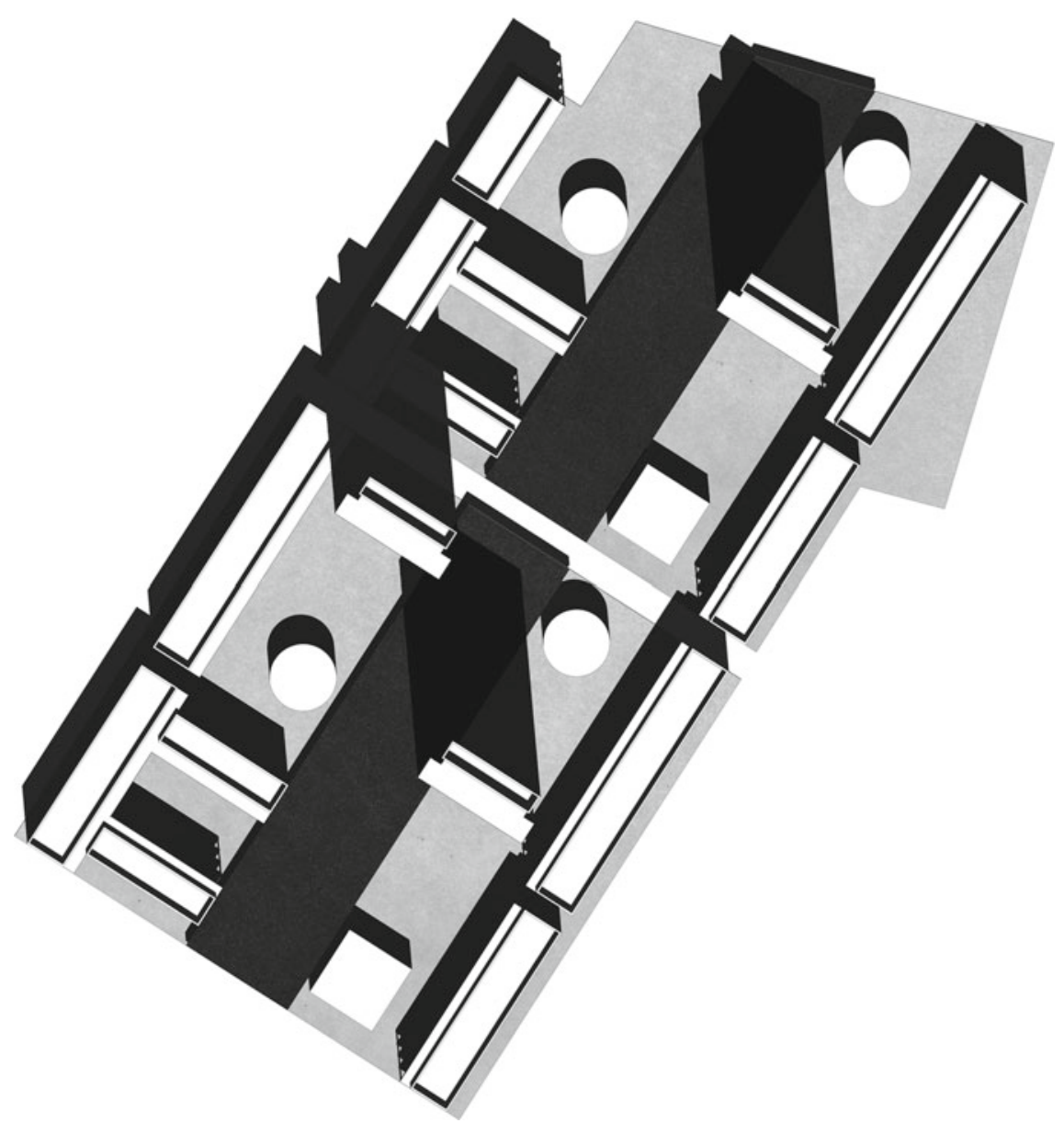

Fig. 3 Housing unit, first variation

a hierarchy of public spaces of different character, a wide range of places, and a variety of views one perceives while walking around the park along its central axis.

The reversed role in terms of public character between the street and the space within the blocks is reflected by a reversal of building solutions and type choices for the house: along the streets the block is defined by low buildings developed towards the interior by porticoes and loggias, with open pathways and passages towards the central green area. The tall houses are located freely within the block, at right angles to the streets, in connection with the park, just like the lower courtyards are open onto the same green area.

This results in a clear definition of outside and inside environment, a separation that in the old city generally kept private and inaccessible space. Here, it simply defines two collective places of different character, with access and distribution roads as 
purely functional pathways, while the places for housing, once more public as they were in the old city, include parks and gardens.

Every unit includes three types of housing: open courtyard housing, aligned housing, and tall housing that organize different places, each with its own character. The more enclosed and intimate $\mathrm{C}$-shaped courtyards close to the longitudinal streets that run through the settlement and partially border the space inside the block are four-storey high and defined by aligned buildings along the streets and two transversal buildings of the same height. The other open courtyards are wider and typically feature a relation between different buildings - the street-facing aligned building, the tall perpendicular house that defines its measure, and a service building on the third side. The common facilities, also located within the blocks, are mainly built along the two longitudinal streets that run through the entire settlement (Fig. 3).

At a larger scale, the tall houses establish a more expansive landscape: they interact between each other at a distance within each block, are conceived in the general plan of the new settlement, and develop a relationship with the towers planned in the front square of the system as new subjects in the comprehensive design of a city made of separate and hopefully recognizable elements, that in turn is part of the Lombard landscape at a broader scale.

\section{The Second Project, 2012. Second Variation ${ }^{4}$}

The variation on the initial plan takes the architecture of the buildings as crucial to the composition as a whole. A block that can be walked through and enjoyed by the community, with no streets open to vehicles, onto which the apartments, facilities, and towers all look. The block is delimited by five-storey buildings where the loggialiving rooms of iron and glass look onto the park in the middle of the block. Sleeping areas and facilities of the apartments look onto tree-lined streets while the loggialiving room becomes the new vantage point to observe the city immersed in nature, the central hub of the home, like the loggia of Gardella's Casa al Parco, which looks straight out onto the Sempione Park almost as though to assert exclusive rights to its use.

Towards the city, the walls of the bedrooms, one level higher, constitute the compact, linear street frontage delimiting the block lengthwise. The apartment buildings are interrupted only at points corresponding to the towers inside the block, creating small squares that differ in each case, and provide lateral access to the residential block as well as a path running all the way through it.

The towers are based on the same principle as the apartment buildings, with a distinction in terms of construction and outlay between the sleeping and living areas.

\footnotetext{
${ }^{4}$ See Footnote 1. Design Group, Tomaso Monestiroli with Claudia Tinazzi, Federica Cattaneo.
} 


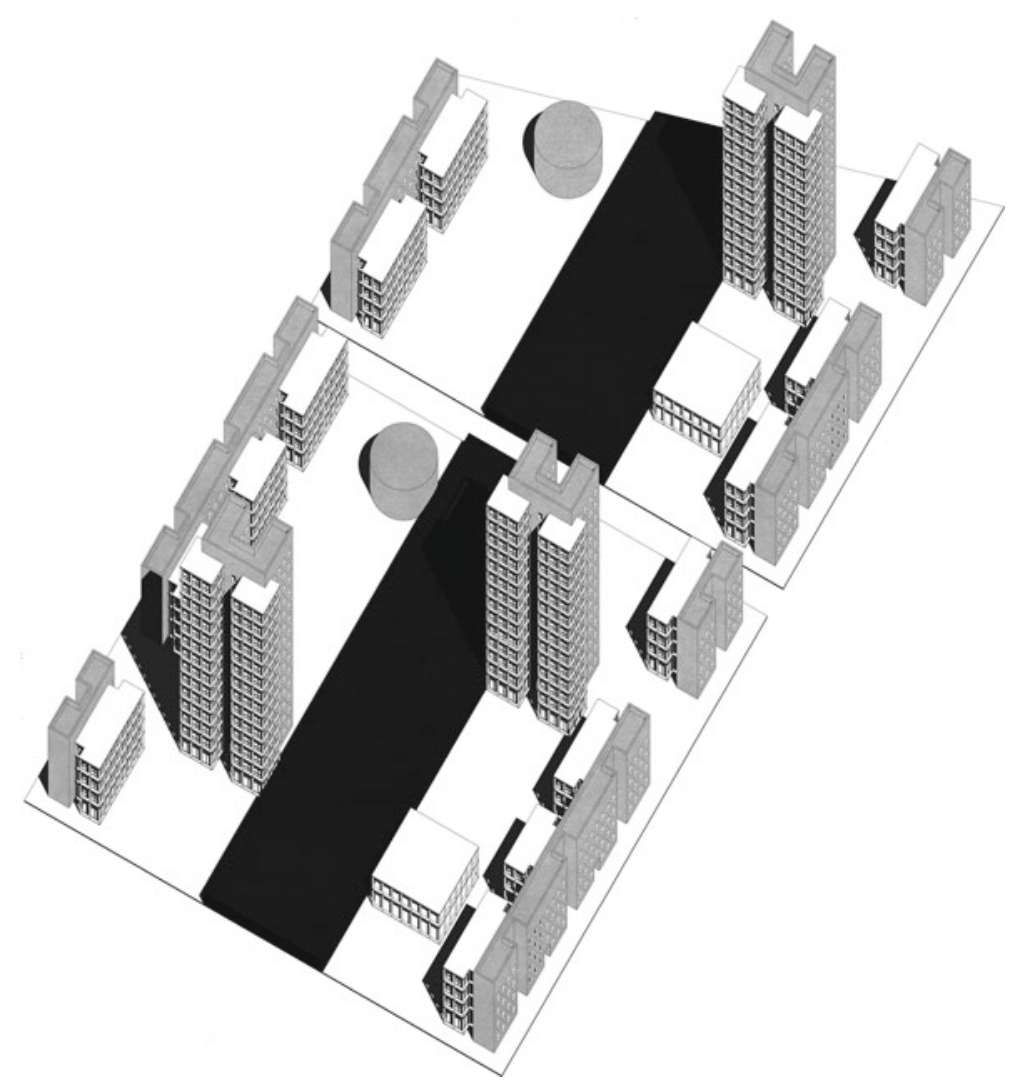

Fig. 4 Housing unit, second variation

The living rooms have full-length windows looking south onto the central avenue and the large public park beyond the railway line. Being 55 metres tall, the towers look out a long way and can be seen from afar, thus making it possible to identify the different relations with the blocks to which they belong and with the city. Perpendicular to the living rooms, the walls of the bedrooms and facilities are oriented east-west. The resulting T-shape encapsulates the importance attached to the view of the city and the natural environment. Located in the green areas of the block after the towers are the collective facilities, which help in turn to develop the relations required for the creation of places of ever increasing complexity and diversity to be discovered and experienced on walking through the block (Fig. 4). 
Open Access This chapter is licensed under the terms of the Creative Commons Attribution 4.0 International License (http://creativecommons.org/licenses/by/4.0/), which permits use, sharing, adaptation, distribution and reproduction in any medium or format, as long as you give appropriate credit to the original author(s) and the source, provide a link to the Creative Commons license and indicate if changes were made.

The images or other third party material in this chapter are included in the chapter's Creative Commons license, unless indicated otherwise in a credit line to the material. If material is not included in the chapter's Creative Commons license and your intended use is not permitted by statutory regulation or exceeds the permitted use, you will need to obtain permission directly from the copyright holder.

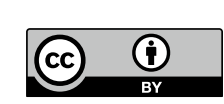

